\title{
Is the emperor wearing new clothes? A social assessment of the European Union 2007-2013 financial framework
}

\section{Fabio Monsalve, Jorge Zafrilla, María-Ángeles Cadarso \& Angela García-} Alaminos

To cite this article: Fabio Monsalve, Jorge Zafrilla, María-Ángeles Cadarso \& Angela García-Alaminos (2018): Is the emperor wearing new clothes? A social assessment of the European Union 2007-2013 financial framework, Economic Systems Research, DOI: 10.1080/09535314.2018.1491391

To link to this article: https://doi.org/10.1080/09535314.2018.1491391

+ View supplementary material $\longleftarrow$

曲 Published online: 03 Jul 2018.

Submit your article to this journal $₫$

View Crossmark data 


\title{
Is the emperor wearing new clothes? A social assessment of the European Union 2007-2013 financial framework
}

\author{
Fabio Monsalve (Da ${ }^{a}$, Jorge Zafrilla (1D ${ }^{a}$, María-Ángeles Cadarso (iD ${ }^{a}$ and Angela \\ García-Alaminos ${ }^{a}$ \\ ${ }^{a}$ Department of Economic Analysis and Finance, University of Castilla-La Mancha, Albacete, Spain
}

\begin{abstract}
Over the years, European leaders have proudly waved a social flag as one of the European Union's (EU) constituent and differentiating elements. This commitment is assessed here through the social footprint of the European 2007-2013 multiannual financial framework among the EU countries and, worldwide, using an extended multiregional input-output model. The focus is on the quantity and the quality of income and jobs generated. We find that wellknown differences among its northern, southern and eastern regions threaten the EU's intentions for high social standards, enabling firstand second-class winners. Core EU countries account for the most of the Funds and, thus, most of the positive economic and social impacts, mainly through spillovers from peripheral regions. Beyond the EU borders, Funds expenditures induce capital compensation boosts in emerging countries not balanced by a similar labor compensation impulse. Indeed, China captures the bulk of low-skilled and temporary employment.
\end{abstract}

\section{ARTICLE HISTORY}

Received 19 May 2017

In final form 8 June 2018

\section{KEYWORDS}

Social footprint; European

Union; supply chains;

multiregional input-output

analysis; employment

\section{Introduction}

In 1952, Jean Monnet, architect of European unity, said 'Nous ne coalison pas de Etats, nous unissons des hommes' or, in English, 'We are not forming coalitions of States, we are uniting men'. This quote encapsulates the deepest intention of European idealization: social commitment. Over time, European leaders have vocally supported such social justice but perhaps have been less financially supportive to that vision compared to other forms of development. The importance of social justice is explicit in Article 3.3 of the Treaty on European Union (EU) which states 'The Union shall combat social exclusion and discrimination, and shall promote social justice and protection, equality between women and men, solidarity between generations and protection of the rights of the child'. And, later in TEU, Article 3.5, the social commitment extends beyond the EU's boundaries: 'In its relations with the wider world ... It shall contribute to peace, security, the sustainable development of the Earth, solidarity and mutual respect among peoples, free and fair trade, eradication of poverty and the protection of human rights...' . All those social guiding principles 
shape the EU's Acquis Communautaire (the body of common rights and obligations that is binding on all the member states), which substantially promotes basic workers' rights and working conditions; universal and sustainable social protection; inclusive labor markets; effective social dialogue; and social cohesion. Not surprisingly, European countries receive the highest scores on the Decent Work Index (Bonnet et al., 2003). Still according to Vaughan-Whitehead (2015, p. 46) 'compared with other countries and regions EU countries are also characterized by high expenditure on social protection, grounded on the principles of solidarity, equality and social cohesion that represent not only the cement but also the "soul" of European "social market economy". Thus, the question is whether this image of the EU as a social Shangri-La is at risk of being shredded due to unintended consequences unleashed by the international fragmentation of the production and the complex ramifications of global value chains associated with enhanced economic globalization. Or, to put this in more literary terms, and paraphrasing Hans Christian Andersen's well-known fairy tale - Is the world's social emperor wearing new clothes?

As is widely known, the EU plays an active role within its boundaries through financial intervention as laid down in its pluriannual budgets, known as financial perspectives or multiannual financial framework (MFF). By funding selected policies and programs, the EU triggers demand shocks in targeted countries. Admittedly, some aspects of those shocks can eventually spill over to its trade partners; therefore, via shockwaves (spillover and leakage effects) should be expected between these EU epicenters (the countries directly targeted by the Fund) and global-value-chain neighbors both inside and outside EU.

An empirical contribution of the present paper is an analysis of the social spillover and leakage effects. The social dimension is evaluated throughout an analysis of income generation and distribution across countries, the employment creation by skill level and some labor-quality indicators, such as temporary and part-time employment. This allows us to assess the extent to which the economic impacts enabled by EU budgetary efforts meet the ambitious social standards set in EU's highest-order document. To assess the relative social impacts within the EU of EU funds, we segregate Europe into three broad regions following a proto-geographical criterion: northern Europe - the 'core', southern Europe Mediterranean countries ones plus Ireland; and eastern Europe - the newcomer economies to the EU. The proposed classification fits with three distinctive 'visions' of the European unity, which subsequently shape the economic role of each within the EU. This is a most pertinent issue because if EU value chains become highly fragmented with high leakages to other regions both inside and outside of the EU, policy-makers should craft multiregional agreements that facilitate desired social goals (Los et al., 2015).

Our research approach relies on the extended multiregional input-output (E-MRIO) model. The model itself accounts for total, direct and indirect, upstream burdens linked to a given economic activity or policy expressed through a selected level of final demand. In our research, changes in final demand are estimates of the expenditures embodied in European Funds from 2007 to 2013. E-MRIO is the best tool for unraveling the intricacies of international supply chains and a suitable, accurate way of measuring global footprints; indeed, it is presently the norm for undertaking such calculations (Wiedmann et al., 2011; Dietzenbacher et al., 2013; Wiedmann, 2015).

The ongoing international fragmentation of production chains, with an increasing share of value added outside the country-of-completion and also the major trade region to which 
the country belongs, suggests a transition from regional production systems to the 'Factory World' (Los et al., 2015). In such a global system in which countries and industries are highly interconnected, microeconomic shocks can propagate worldwide and induce macroeconomic fluctuations (Kali and Reyes, 2007; Cerina et al., 2015). For instance, a static shock in an epicenter's final demand can trigger dynamic changes in that nation's key sectors; these, in turn, can affect final demands of other countries. Such higher-order effects can cause stronger spillovers via demand shocks than can direct trade links themselves (Kireyev and Leonidov, 2015; Andritzky et al., 2016; Kireyev and Leonidov, 2016; Tran et al., 2017). Focusing on the EU region, Alatriste-Contreras (2015) shows that the most central sectors to the EU not only diffuse more broadly but also yield a greater aggregate economic impact on the EU. Baldwin and Lopez-Gonzalez (2015), for their part, consider Europe as a hub-and-spoke system in which Germany, the United Kingdom and France are the hubs or 'headquarters economies' that trade with a wide range of partners. On the other hand, peripheral or 'spoke' European countries depend heavily on nearby advancedtechnology economies. Although peripheral areas received more funds, the intra-regional network generates intense leakage from the peripheral economies into core economies. In contrast, the opposite leakage from core to periphery appears to be weaker, at least according to the Hobza, Zeugner and Martins (2012) and Picek and Schröder (2017). All in all, these studies suggest that the EU is couched within an interdependent, complex global network; and it is this global network, not individual countries or regions, that frames our analysis for mapping the social footprint of the EU financial instruments.

Prior to E-MRIO analysis, social footprints were tough to tackle. Data inaccessibility was a key issue since satellite social accounts for most MRIO databases are limited (McBain, 2014); So researchers had to develop their own, as we do here. Yet, recent case studies do exist on social dimensions. Most address labor and related issues from diverse perspectives: the master-servant relationships between developed and developing countries (Alsamawi et al., 2014a); the dependence of quasi-egalitarian economies on imports from clear non-egalitarian economies (Alsamawi et al., 2014b); differences in principles and working rights at the international level (Gómez-Paredes et al., 2015), 'bad labor footprints' (Simas et al., 2014); the presence of child labor (in the previously cited articles) and the extremely low cost of substituting them in India (Gómez-Paredes et al., 2016); or health and safety at work (Alsamawi et al., 2017). Sometimes, the social dimension is emphasized inside the global concept of sustainability, including economic and environmental aspects (Rodríguez-Serrano et al., 2016) or connecting with the social development goals (Xiao et al., 2017b) and with the EU Sustainable Development Strategy (Pelletier et al., 2018). Table S1 in online supplementary information (SI) to this paper compares indicators, data sources and the scope of literature that explores social sustainability through E-MRIO. In a nutshell, the literature depicts the social consequences of an interconnected world; even though none of it deals with a deliberate demand shock per se. Thus, this is our contribution to the literature since European Funds can have co-benefits and adverse side effects in the social sphere that need systematic empirical investigation that E-MRIO can yield. We also extend the range of social indicators to assess both the quantity and the quality of income and job generation considering each EU region peculiarities.

In line with most of the literature we find that developed countries not only are the economic winners but also the social winners during the present era of globalization. We also 
demonstrate that, in fact, EU policies reinforce this state of affairs. Indeed, the EU is operating economically at multiple-speeds (Rakauskienè and Kozlovskij, 2014), which affects how social impacts unfold within its borders, even though EU Funds may be distributed with the best of intentions. As a consequence, we find that the European MFF as a whole, not just European Agricultural Fund for Rural Development as investigated by Monsalve et al. (2016), winds up mainly benefiting Europe's most developed economies. Thus, the MFF actually appear to accentuate the gap between targeted and nontargeted countries rather than narrowing it - the social emperor seems to be wearing the same, old clothes.

\section{Materials and methods}

In this section, we present the methods used in this study and describe the data foundation. We start by describing the fundamentals of E-MRIO and its extensions for computing footprints. We then detail the data sources and, specifically, the manner in which we elaborate demand.

\subsection{E-MRIO analysis}

Standard E-MRIO measures the production requirements and the associated environmental impacts required to meet a selected level of final demand within a supply chain (Davis and Caldeira, 2010; Steen-Olsen et al., 2012; Wiedmann et al., 2013). Given the increasing national and international attention to social concerns, extensions of MRIO to social dimensions are a natural next step (Hardadi and Pizzol, 2017). A global MRIO framework, includes regions and nations with technology, and trade is divided into intermediate trade, with specific industry destinations, and final trade. The basic E-MRIO equation is as follows: $\mathbf{F}=\hat{\mathbf{f}}(\mathbf{I}-\mathbf{A})^{-1} \hat{\mathbf{y}}$, where $\hat{\mathbf{f}}$ is the target factor (either environmental or social) diagonalized vector per unit of output, $(\mathbf{I}-\mathbf{A})^{-1}$ is the Leontief inverse matrix, and $\hat{\mathbf{y}}$ is the diagonalized final demand per country (Miller and Blair, 2009; Monsalve et al., 2016). $\mathbf{A}$ is the matrix of technical coefficients in a MRIO context, providing a detailed sectorby-sector and region-by-region domestic intraregional structure and the trade matrices from one region to another. To work with matrix forms in footprint estimations, MRIO contexts provide more precise information; in this sense, we must also process the final demand vectors. Similar to the technical coefficients matrix, the isolation of domestic and final demand trade vectors between regions is required. The extension of the model to compute different impacts is estimated by pre-multiplying the Leontief Inverse Matrix by target factors provided by different satellite accounts. The diagonalization of those target factor vectors $(\hat{\mathbf{f}})$ enables the estimation of multipliers and results in matrix form (Skelton et al., 2011; Cadarso et al., 2012; Meng et al., 2014). F can be analyzed in different perspectives. The rows of $\mathbf{F}$ show the distribution of the impact that occurs in one sector of a country when produced to attend all sectors and countries. This is the so-called production based-approach. Conversely, the columns of $\mathbf{F}$ yield the impacts global impacts across sectors of the production of a unit of final demand in a country. This is the consumptionbased approach (CBA) or factor footprint concept. Given that the present study assesses the social pressures driven by the EU MFF across the world, we follow the CBA criteria to include the whole global production chains. 
When the international trade is under analysis, E-MRIO models provide complete and unique detail of the international supply chains in terms of impacts, information that other models cannot yield. Triple bottom line (TBL) analysis assesses the economic, social and environmental outcomes of reviewed policies (Foran et al., 2005; Wood and Garnett, 2010; Kucukvar et al., 2014). Specifically, Monsalve et al. (2016) have used TBL to determine the global losses or gains from intra-EU and non-intra-EU trade relations on target regions due to trade changes from EFARD. We broaden the political scope by evaluating MFF as a whole. Thus, our elaboration of the structure of final demand in terms of MFF expenditures, as nested in the E-MRIO analysis, is a key contribution of the present work. We focus on the social dimension since social aspects tend to receive less attention than do economic or environmental aspects. Specifically, we evaluate the effects on such World Input-Output Database (WIOD) measures (Timmer et al., 2015) as labor compensation by skill category, capital compensation, and employment by skill category, and to them we add our own indicators for temporary and part-time employment (see Table S2 in SI). The distinctions between wages and capital compensation and between skill levels and regions where the employment and income are generated are reasonable proxies for the potential social impacts of the European Funds expenditure (Simas et al., 2014).

\subsection{Data processing}

The following have been used as data foundations of this work:

(1) WIOD. This dataset provides, (1) the global interindustry transactions data covering 35 sectors and 40 countries plus one rest of the world (RoW) region; (2) some socioeconomic satellite accounts used in the course of this study; (a) labor by skill category and (b) capital compensation as well as hours worked by skill category; and, (3) the price levels of gross output, intermediate inputs and value added required to deflate WIOD tables and compensation-satellite-accounts. The available and useful data for our purposes covers 2007-2009.

(2) Fourth MFF (2007-2013) of the EU (European Commission, 2015). This financial dataset feeds the final demand of the model

(3) EUROSTAT, Labour Force Survey, LFS (European Commission, 2016), ILOSTAT database (ILO, 2016), ASPIRE (The World Bank, 2016), and other data from selected statistical national agencies. These sources have been used to build the temporary and partial employment satellite accounts at the ISIC-Rev.3 disaggregation level (18 sectors). By merging these sources with WIOD, we do not compromise comparability, at least according to EUROSTAT (2017a; 2017b) and Erumban et al. (2012). This is because WIOD uses labor data from ESTAT National Accounts and because LFS is frequently an input to employment estimates in national accounts since it is both broadly comparable in terms of employment growth (see SI online for possible sources of divergence). In addition, although ILO concepts reflect the concepts in national accounts, ILO has separate aims and measurement approaches, which in turn could lead to different results. EUROSTAT also provides price levels to deflate EU financial datasets. 
We deflated all data - WIOD, the compensation satellite accounts and the EU's MFF using the aforementioned price levels to the year 2009, which we assign as the base-year since it is the last available via WIOD. Of course, the specific year used as the base year does not matter once all prices are in real terms. The model was solved in 2009 constant prices, year by year from 2007 to 2013 at the maximum level of disaggregation (35 sectors and 41 countries/regions); after that, we summed results across the seven-year period.

As previously stated, the E-MRIO analysis allows weighting direct and indirect effects of for a pre-determined level of final demand. Therefore, to capture the consequences of a selected policy, we first had to allocate the all EU budget line items to targeted sectors and countries. This resulted in a harmonized country-sector vector that formed the final demand vector for our exercise. The operation itself was nontrivial, given the different sector classifications between the two main databases: 35 industries in WIOD and 18 (ISIC Rev. 3) for the social indicators that we developed. First, we redistributed the funds to the 35 WIOD sectors; see Table S4 in SI and notes to look into total amounts and exclusions, and also Table S7 in SI for reports used. After that, we aggregated both the WIOD table and the final demand vector to 15 of the 18 ISIC Rev.3 sectors ('Agriculture' and 'Fishing' were aggregated as in WIOD; and 'territorial organizations and bodies' and 'not elsewhere classified' discarded because their low numbers and difficulties to allocate) following the correspondences in Table S3 of the SI, which is available online.

Table S5 and S6 in the SI show the share and amount of each budget heading as allocated to the 15 ISIC Rev. 3 sectors. Here we clarify two matters pertaining to the way we allocated funds to final demand. The detail (or lack thereof) provided by each EU report on the MFF conditions our sectoral and country allocations. For example, reports on Cohesion and Agricultural Policies gave sufficient detail for $78 \%$ of the total budget-to allow us to distribute funds easily across both sectors and countries. For the remaining $22 \%$ of the budget we allocated by sector based only a description of the project and in many cases were forced to allocate across sectors and country by using information on the $78 \%$ for which we had near-perfect information (see Table S7 and its notes in the SI). Also, a nonnegligible part of the funds is a set of direct transfers to targeted households (particular demographic or income groups). We assigned such transfers to 'Final-consumption-expenditure-byhouseholds' sector in WIOD; this means we necessarily also assumed that the receivers of the transfers consume goods and services in the same shares as does the average consumer in the assigned country.

\section{Results and discussion}

Much literature discusses the dominance of either regional or global relationships in supply chains (Baldwin and Lopez-Gonzalez, 2015; Los et al., 2015). We find that the main economic beneficiaries, both direct and indirect, of the European policies are member states with small fractions of the value added (12\%) that leak out worldwide (that boost outside economies). This points to the importance of so-called 'factory Europe' (Baldwin and Lopez-Gonzalez, 2015) in fulfilling the demand triggered by European Funds. A different composition of this demand (for example, a demand highly concentrated in the durables goods) could lead to a more dominating role of global relationships instead of those more regional - more internal to the EU (Bems et al., 2010). In the regional network linked to the demand created by EU funds, northern European countries like Germany or the 
United Kingdom are core economies, which are deeply integrated into European supplychains, while economies of southern and eastern European countries are more peripheral, as defined by their heavy dependence on just a handful of trade partners. As a consequence of this structure, there clear are first- and second-class winners within the EU. Northern EU countries, which perform best on the Global Competitiveness Index (Priede and Neuert, 2015), receive absolutely and proportionally more capital and labor compensation than do southern and eastern EU countries (see Table 1 for the results and countries in each group). The differences are even starker when we examine the findings for skilled categories of labor; Northern countries receive nearly half of the total compensation received by all EU high- and medium-skilled labor ( $47 \%$ and $46 \%$ respectively) but only just over a quarter $(29 \%)$ of the compensation received by all EU low-skilled labor. In addition, a focus on the hours worked, rather than compensation received, further widens the apparent discrepancies, leading to social results that differ markedly from the economic ones already reported. That is, a relevant part of the total hours worked (34\%) are 'imported' into Europe and mainly in the form of low-skilled labor. Within the EU, hours worked are concentrated in eastern and southern Europe, even for high- and medium-skilled labor.

Our general set of findings is in line with those of other studies. The main positive effects of global value chains positive are retained by developed countries, while less positive effects spill over into developing economies via international trade (Alsamawi et al., 2014a). Our results are notable in highlighting that expenditures emanating from European Funds reinforce and deepen these broader trends, rather than offset them as intended. This is demonstrated in Figure S1 in the online SI, which reveals what appears to be a pattern of negative impacts pattern from European Funds, both outside and inside the EU, in the form of more hours worked, more temporary employment and lower compensation per worker for all kinds of skills (except for low-skilled labor) than the business as usual (BAU) performance of the economy.

\subsection{The socioeconomic impact of European policies: an indicator-by-indicator analysis}

In general, European Funds are widely dispersed across the EU. Still, member countries in the south and east are endowed with 75\% more funding per inhabitant than are member countries in the north. Despite this differential, peripheral countries (those in the EU south and east) accrue just $48 \%$ of the total VA generated globally by the spending of those Funds - 12 percentage points less than their initial endowment share, while the EU core gets nearly the same share (39\%); the remaining $12 \%$ leaks to other world regions.

A more detailed analysis of income distribution identifies further limitations of the benefits ultimately allocated to peripheral countries. Northern EU countries obtain 43\% of all labor compensation benefits of the MFF, but southern and eastern EU countries get just $31 \%$ and $19 \%$, respectively. Wage gaps and sparser interindustry structures in peripheral further boost the net benefits per worker for northern EU economies. They are three and six times higher than they are for southern and eastern countries despite similar or even larger degrees of leakage exhibited by economies of northern EU nations (29-31\% and $31-35 \%$ of southern and eastern parts of the EU, respectively, compared to $37-38 \%$ observed in its north). Kali and Reyes (2007) note that human capital and international economic integration are complements. While Baldwin and Lopez-Gonzalez, (2015) 


\begin{tabular}{|c|c|c|c|c|c|c|c|c|c|c|c|c|c|c|}
\hline \multirow{3}{*}{ FUNDS BENEFICIARY } & \multirow{3}{*}{$\begin{array}{l}\text { EU-FUNDS (Million } € \text { ) } \\
\text { per capita }(€)\end{array}$} & \multirow{3}{*}{$\begin{array}{r}\text { NORTHERN EU } \\
\mathbf{2 8 8 , 0 3 5 . 5} 40 \% \\
\mathbf{1 , 0 8 2 . 6} 22 \%\end{array}$} & \multirow{2}{*}{$\begin{array}{l}\text { SOUTHERN EU } \\
250,024.234 \%\end{array}$} & EASTERN EU & \multicolumn{2}{|c|}{ NAFTA } & \multicolumn{2}{|c|}{ CHINA } & \multicolumn{2}{|c|}{ EAST ASIA } & \multicolumn{2}{|c|}{ BRIIAT } & \multicolumn{2}{|l|}{ RoW } \\
\hline & & & & $192,029.226 \%$ & 0.0 & $0 \%$ & 0.0 & $0 \%$ & 0.0 & $0 \%$ & 0.0 & $0 \%$ & 0.0 & $0 \%$ \\
\hline & & & $\mathbf{1 , 8 8 8 . 2} 39 \%$ & $1,892.439 \%$ & 0.0 & $0 \%$ & 0.0 & $0 \%$ & 0.0 & $0 \%$ & 0.0 & $0 \%$ & 0.0 & $0 \%$ \\
\hline \multirow[t]{18}{*}{ VALUE ADDED } & TOTAL (Million $€$ ) & $266,976.239 \%$ & $199,076.729 \%$ & 131,389.6 19\% & $17,151.6$ & $3 \%$ & $13,968.7$ & $2 \%$ & $8,225.8$ & $1 \%$ & $15,967.5$ & $2 \%$ & $24,453.0$ & $4 \%$ \\
\hline & CAPITAL COMPENSATION & $\mathbf{9 4 , 0 3 7 . 4 3 5 \%}$ & $72,618.727 \%$ & $\mathbf{5 5 , 7 9 0 . 8 2 1 \%}$ & $8,803.0$ & $3 \%$ & $8,763.0$ & $3 \%$ & $3,722.4$ & $1 \%$ & $8,362.4$ & $3 \%$ & $18,723.4$ & $7 \%$ \\
\hline & Domestic impact & $70,918.238 \%$ & $64,740.235 \%$ & $50,061.727 \%$ & 0.0 & $0 \%$ & 0.0 & $0 \%$ & 0.0 & $0 \%$ & 0.0 & $0 \%$ & 0.0 & $0 \%$ \\
\hline & Leakage & $32,761.438 \%$ & $25,285.230 \%$ & $27,054.432 \%$ & 0.0 & $0 \%$ & 0.0 & $0 \%$ & 0.0 & $0 \%$ & 0.0 & $0 \%$ & 0.0 & $0 \%$ \\
\hline & Boost & $23,119.3 \quad 27 \%$ & $7,878.5 \quad 9 \%$ & $5,729.1 \quad 7 \%$ & $8,803.0$ & $10 \%$ & $8,763.0$ & $10 \%$ & $3,722.4$ & $4 \%$ & $8,362.4$ & $10 \%$ & $18,723.4$ & $22 \%$ \\
\hline & LABOR COMPENSATION & $172,938.843 \%$ & $126,458.031 \%$ & $\mathbf{7 5 , 5 9 8 . 8} 19 \%$ & $8,348.6$ & $2 \%$ & $5,205.7$ & $1 \%$ & $4,503.5$ & $1 \%$ & $7,605.2$ & $2 \%$ & $5,729.6$ & $2 \%$ \\
\hline & HIGH SKILLED & $72,203.547 \%$ & $45,337.630 \%$ & $26,954.818 \%$ & $3,705.2$ & $3 \%$ & 477.3 & $0 \%$ & $1,742.9$ & $1 \%$ & $1,763.5$ & $1 \%$ & $1,129.4$ & $1 \%$ \\
\hline & Domestic impact & $56,569.246 \%$ & $42,081.134 \%$ & $25,158.2 \quad 20 \%$ & 0.0 & $0 \%$ & 0.0 & $0 \%$ & 0.0 & $0 \%$ & 0.0 & $0 \%$ & 0.0 & $0 \%$ \\
\hline & Leakage & $10,801.3 \quad 37 \%$ & $8,962.130 \%$ & $9,742.3 \quad 33 \%$ & 0.0 & $0 \%$ & 0.0 & $0 \%$ & 0.0 & $0 \%$ & 0.0 & $0 \%$ & 0.0 & $0 \%$ \\
\hline & Boost & $15,634.353 \%$ & $3,256.5 \quad 11 \%$ & $1,796.5 \quad 6 \%$ & $3,705.2$ & $13 \%$ & 477.3 & $2 \%$ & $1,742.9$ & $6 \%$ & $1,763.5$ & $6 \%$ & $1,129.4$ & $4 \%$ \\
\hline & MEDIUM SKILLED & $76,401.246 \%$ & $37,965.623 \%$ & $\mathbf{3 7 , 5 2 1 . 3 2 2 \%}$ & $4,233.1$ & $3 \%$ & $1,913.9$ & $1 \%$ & $2,282.7$ & $1 \%$ & $4,005.8$ & $2 \%$ & $3,514.5$ & $2 \%$ \\
\hline & Domestic impact & $55,531.0 \quad 45 \%$ & $33,532.527 \%$ & $33,234.627 \%$ & 0.0 & $0 \%$ & 0.0 & $0 \%$ & 0.0 & $0 \%$ & 0.0 & $0 \%$ & 0.0 & $0 \%$ \\
\hline & Leakage & $16,779.6 \quad 37 \%$ & $13,034.0 \quad 29 \%$ & $15,726.435 \%$ & 0.0 & $0 \%$ & 0.0 & $0 \%$ & 0.0 & $0 \%$ & 0.0 & $0 \%$ & 0.0 & $0 \%$ \\
\hline & Boost & $20,870.246 \%$ & $4,433.1 \quad 10 \%$ & $4,286.7 \quad 9 \%$ & $4,233.1$ & $9 \%$ & $1,913.9$ & $4 \%$ & $2,282.7$ & $5 \%$ & $4,005.8$ & $9 \%$ & $3,514.5$ & $8 \%$ \\
\hline & LOW SKILLED & $\mathbf{2 4 , 3 3 4 . 1 2 9 \%}$ & $\mathbf{4 3 , 1 5 4 . 8 5 1 \%}$ & $11,122.813 \%$ & 410.3 & $0 \%$ & $2,814.5$ & $3 \%$ & 477.8 & $1 \%$ & $1,835.9$ & $2 \%$ & $1,085.6$ & $1 \%$ \\
\hline & Domestic impact & $17,853.2 \quad 27 \%$ & $38,593.0 \quad 58 \%$ & $9,973.9 \quad 15 \%$ & 0.0 & $0 \%$ & 0.0 & $0 \%$ & 0.0 & $0 \%$ & 0.0 & $0 \%$ & 0.0 & $0 \%$ \\
\hline & Leakage & $7,177.138 \%$ & $5,846.931 \%$ & $5,791.6 \quad 31 \%$ & 0.0 & $0 \%$ & 0.0 & $0 \%$ & 0.0 & $0 \%$ & 0.0 & $0 \%$ & 0.0 & $0 \%$ \\
\hline & Boost & $6,480.934 \%$ & $4,561.8 \quad 24 \%$ & $1,148.9 \quad 6 \%$ & 410.3 & $2 \%$ & $2,814.5$ & $15 \%$ & 477.8 & $3 \%$ & $1,835.9$ & $10 \%$ & $1,085.6$ & $6 \%$ \\
\hline \multirow[t]{13}{*}{ WORKED HOURS } & TOTAL (Million hours) & $\mathbf{6 , 5 3 4 . 9} 15 \%$ & $\mathbf{7 , 9 1 7 . 8} 18 \%$ & $13,895.732 \%$ & 672.0 & $2 \%$ & $5,933.5$ & $14 \%$ & 445.7 & $1 \%$ & $4,217.5$ & $10 \%$ & $3,419.7$ & $8 \%$ \\
\hline & HIGH SKILLED & $1,927.924 \%$ & $1,795.322 \%$ & $2,995.137 \%$ & 294.6 & $4 \%$ & 316.4 & $4 \%$ & 144.9 & $2 \%$ & 344.8 & $4 \%$ & 304.4 & $4 \%$ \\
\hline & Domestic impact & $1,547.0 \quad 26 \%$ & $1,667.1 \quad 28 \%$ & $2,816.547 \%$ & 0.0 & $0 \%$ & 0.0 & $0 \%$ & 0.0 & $0 \%$ & 0.0 & $0 \%$ & 0.0 & $0 \%$ \\
\hline & Leakage & $727.238 \%$ & $539.529 \%$ & $625.733 \%$ & 0.0 & $0 \%$ & 0.0 & $0 \%$ & 0.0 & $0 \%$ & 0.0 & $0 \%$ & 0.0 & $0 \%$ \\
\hline & Boost & $380.920 \%$ & $128.1 \quad 7 \%$ & $178.69 \%$ & 116.0 & $6 \%$ & 316.4 & $17 \%$ & 144.9 & $8 \%$ & 344.8 & $18 \%$ & 304.4 & $16 \%$ \\
\hline & MEDIUM SKILLED & $\mathbf{3 , 3 1 0 . 2} 17 \%$ & $\mathbf{2 , 3 7 6 . 4} 13 \%$ & $7,643.940 \%$ & 286.1 & $2 \%$ & $1,954.5$ & $10 \%$ & 229.2 & $1 \%$ & $1,649.6$ & $9 \%$ & $1,503.1$ & $8 \%$ \\
\hline & Domestic impact & $2,469.2 \quad 22 \%$ & $2,145.2 \quad 19 \%$ & $6,835.960 \%$ & 0.0 & $0 \%$ & 0.0 & $0 \%$ & 0.0 & $0 \%$ & 0.0 & $0 \%$ & 0.0 & $0 \%$ \\
\hline & Leakage & $2,954.339 \%$ & $2,022.9 \quad 27 \%$ & $2,525.434 \%$ & 0.0 & $0 \%$ & 0.0 & $0 \%$ & 0.0 & $0 \%$ & 0.0 & $0 \%$ & 0.0 & $0 \%$ \\
\hline & Boost & $841.0 \quad 11 \%$ & $231.23 \%$ & $808.0 \quad 11 \%$ & 286.1 & $4 \%$ & $1,954.5$ & $26 \%$ & 229.2 & $3 \%$ & $1,649.6$ & $22 \%$ & $1,503.1$ & $20 \%$ \\
\hline & LOW SKILLED & 1,296.8 $8 \%$ & $3,746.123 \%$ & $3,256.720 \%$ & 91.3 & $1 \%$ & $3,662.5$ & $23 \%$ & 71.7 & $0 \%$ & $2,223.2$ & $14 \%$ & $1,612.2$ & $10 \%$ \\
\hline & Domestic impact & $967.213 \%$ & $3,396.347 \%$ & $2,923.540 \%$ & 0.0 & $0 \%$ & 0.0 & $0 \%$ & 0.0 & $0 \%$ & 0.0 & $0 \%$ & 0.0 & $0 \%$ \\
\hline & Leakage & $3,594.4 \quad 41 \%$ & $2,439.1 \quad 28 \%$ & $2,639.930 \%$ & 0.0 & $0 \%$ & 0.0 & $0 \%$ & 0.0 & $0 \%$ & 0.0 & $0 \%$ & 0.0 & $0 \%$ \\
\hline & Boost & $329.5 \quad 4 \%$ & $349.8 \quad 4 \%$ & $333.34 \%$ & 91.3 & $1 \%$ & $3,662.5$ & $42 \%$ & 71.7 & $1 \%$ & $2,223.2$ & $26 \%$ & $1,612.2$ & $19 \%$ \\
\hline
\end{tabular}

Table 1. EU funds spillover by indicator and region. 
Table 1. Continued.

\begin{tabular}{|c|c|c|c|c|c|c|c|c|c|c|c|c|c|c|c|c|c|}
\hline \multirow[b]{2}{*}{$\begin{array}{l}\text { AVERAGE HOURLY } \\
\text { WAGES }\end{array}$} & \multirow[b]{2}{*}{$\begin{array}{l}\text { AVERAGE HOURLY WAGE } \\
\text { (PPP } € / \text { hour) }\end{array}$} & \multicolumn{2}{|c|}{ NORTHERNEU } & \multicolumn{2}{|c|}{ SOUTHERNEU } & \multicolumn{2}{|c|}{ EASTERN EU } & \multicolumn{2}{|c|}{ NAFTA } & \multicolumn{2}{|c|}{ CHINA } & \multicolumn{2}{|c|}{ EAST ASIA } & \multicolumn{2}{|c|}{ BRIIAT } & \multicolumn{2}{|c|}{ RoW } \\
\hline & & 21.6 & - & 19.5 & - & 9.5 & - & 5.0 & - & 2.7 & - & 10.2 & - & 8.3 & - & 2.7 & - \\
\hline & HIGH-SKILLED & 29,6 & - & 26,9 & - & 14,9 & - & 11,6 & - & 3,6 & - & 13,4 & - & 21,0 & - & 6,0 & - \\
\hline & MEDIUM-SKILLED & 21,9 & - & 16,9 & - & 8,8 & - & 9,2 & - & 2,3 & - & 9,4 & - & 8,4 & - & 3,8 & - \\
\hline & LOW-SKILLED & 17,9 & - & 13,9 & - & 8,0 & - & 1,7 & - & 1,8 & - & 8,1 & - & 5,4 & - & 1,1 & - \\
\hline \multirow[t]{8}{*}{ LABOUR MARKET } & $\begin{array}{l}\text { TEMPORARY } \\
\text { EMPLOYMENT (thousands) }\end{array}$ & 457.7 & $10 \%$ & 645.5 & $14 \%$ & 874.1 & $19 \%$ & 20.3 & $0 \%$ & $1,985.4$ & $43 \%$ & 23.1 & $0 \%$ & 431.0 & $9 \%$ & 195.6 & $4 \%$ \\
\hline & Domestic impact & 363.5 & $21 \%$ & 574.9 & $33 \%$ & 806.0 & $46 \%$ & 0.0 & $0 \%$ & 0.0 & $0 \%$ & 0.0 & $0 \%$ & 0.0 & $0 \%$ & 0.0 & $0 \%$ \\
\hline & Leakage & $1,165.6$ & $40 \%$ & 746.5 & $26 \%$ & 976.1 & $34 \%$ & 0.0 & $0 \%$ & 0.0 & $0 \%$ & 0.0 & $0 \%$ & 0.0 & $0 \%$ & 0.0 & $0 \%$ \\
\hline & Boost & 94.2 & $3 \%$ & 70.6 & $2 \%$ & 68.1 & $2 \%$ & 20.3 & $1 \%$ & $1,985.4$ & $69 \%$ & 23.1 & $1 \%$ & 431.0 & $15 \%$ & 195.6 & $7 \%$ \\
\hline & $\begin{array}{l}\text { PART-TIME EMPLOYMENT } \\
\text { (thousands) }\end{array}$ & $1,025.7$ & $31 \%$ & 531.3 & $16 \%$ & 562.6 & $17 \%$ & 39.6 & $1 \%$ & 0.7 & $0 \%$ & 29.6 & $1 \%$ & 870.9 & $27 \%$ & 208.0 & $6 \%$ \\
\hline & Domestic impact & 827.2 & $46 \%$ & 453.1 & $25 \%$ & 516.4 & $29 \%$ & 0.0 & $0 \%$ & 0.0 & $0 \%$ & 0.0 & $0 \%$ & 0.0 & $0 \%$ & 0.0 & $0 \%$ \\
\hline & Leakage & 677.8 & $46 \%$ & 406.1 & $28 \%$ & 387.8 & $26 \%$ & 0.0 & $0 \%$ & 0.0 & $0 \%$ & 0.0 & $0 \%$ & 0.0 & $0 \%$ & 0.0 & $0 \%$ \\
\hline & Boost & 198.6 & $13 \%$ & 78.2 & $5 \%$ & 46.2 & $3 \%$ & $39 n 6$ & $3 \%$ & 0.7 & $0 \%$ & 29.6 & $2 \%$ & 870.9 & $59 \%$ & 208.0 & $14 \%$ \\
\hline
\end{tabular}

Sources: Own estimations. PPP data elaborated from (OCDE, 2017), labor compensation and worked hours by skill elaborated from WIOD. Temporary and Part-time employment elaborated from LFS-Eurostat, ILOSTAT and ASPIRE and the first one does not include self-employed persons by definition (see SI for sources of divergences). NORTHERN EU: Austria, Belgium, Germany, Denmark, Finland, France, United Kingdom, Luxembourg, Netherlands and Sweden. SOUTHERN EU:Spain, Greece, Ireland, Italy and Portugal. EASTERN EU: Bulgaria, Cyprus, Czech Republic, Estonia, Hungary, Lithuania, Latvia, Malta, Poland, Romania, Slovakian Republic and Slovenia. NAFTA: United States, Mexico and Canada. BRIIAT: Brazil, Russia, India, Indonesia, Australia and Turkey. East Asia: Japan, Taiwan and Korea. RoW: rest of the world. Boost and leakage definitions: boost is the indirect impact received by a country triggered by other's countries final demand linked to the Funds. The indirect impact is a boost for the receiving country and a leakage for the country that is sending it. The boosts and the leakages of each of the three European big regions are the aggregations of the boosts and leakages generated individually in each country. 
acknowledge that northern EU countries are 'core' to Europe's supply-chain networks, they still found the positive effects of its higher levels of human capital to be higher than expected. This same agglomerative effect of industry integration might also explain the higher share of labor compensation in northern Europe (43\%) than its share of total value added (39\%).

We observe comparable results for capital compensation. In this case, however, the leakage to the RoW regions is much more relevant (it accounts for $18 \%$ of total capital compensation). The increasingly intensive trade relationships between the EU and developing economies as well as the rising world presence of EU multinational firms enable this leakage of European Funds.

The economic discrepancies of findings for countries inside and outside of the EU are pronounced even more via a footprint in terms of labor hours. In this instance, the RoW provides $35 \%$ of all work hours required to attend to EU Funds spending (compared to just $8 \%$ for compensation). Labor hours within the EU account for $65 \%$. The core-peripheral relationship switches, however, with the EU's northern and southern countries accounting for just $15 \%$ and $18 \%$ of labor hours, respectively, while its eastern countries account for $32 \%$. The peripheral EU regions, particularly the east, are performing as labor-intensive 'factories'. Furthermore, the distinction of labor hours worked by skill level accentuate the matter even further. Low-skilled hours worked accounts for only $8 \%$ in northern EU countries, but $43 \%$ for southern and eastern EU countries combined and $48 \%$ for the RoW. Underlining this disparity are China and BRIIAT (Brazil, Russia, India, Indonesia, Australia, and Turkey), which maintain $23 \%$ and $14 \%$ of the total, respectively. Conversely, hours worked by high- and medium-skilled labor are generated mainly within the EU and in higher shares than are hours worked by low-skilled labor. This imbalance observed between value added generated and the hours required to produce the goods and services by skill clues into potential global inequalities in terms of the quality of the work generated by European Funds. It demonstrates Feenstra (2007) hypothesis about the outsourcing of lower-skilled jobs. It also reaffirms the so-called 'race to the bottom' observed by Xiao et al. (2017a).

This general pattern is also highlighted by an analysis of average hourly wages in terms of purchasing power parity (PPP). For each of the labor skills analyzed, northern EU countries have higher wages than do the other two EU areas. Similarly, on average, workers within the EU as a whole tend to earn more money per hour than do workers in of its trading-partner nations throughout the RoW. Within the EU, these differences explain how northern EU countries retain a higher share of the wages generated by the Funds, while the higher shares in terms of hours are in eastern EU countries. NAFTA is somewhat of an outlier, however; its results for high-skilled labor are similar to those for northern EU countries, but the gap for the rest of the jobs is more akin to those obtained for southern and eastern EU nations. While this seems to be a bit of an enigma, these countervailing facts could be explained by the aggregation in single area of three very different economies: a highly developed and equal economy (Canada), a developing and unequal economy (Mexico), and a highly developed and unequal one (United States), as discussed by Alsamawi et al. (2014b). The case of developing economies like China, BRIIAT and the RoW is important. They are labor intensive with very low wages; So, in this respect they could have clear comparative advantages compared to capital-intensive, high-wage region like Europe, at least so long as transactions and transportation costs are negligible. Clearly 
European Funds are facilitating Simas et al.'s (2014) 'bad labor footprint', which gets at the idea of developed regions enabling and expanding poor labor conditions in developing regions.

By examining the footprints of temporary and part-time labor we can identify differences in the maturity and flexibility of the labor markets (Table 1). Neither indicator is directly tied to negative social impacts; but the concentration of temporary and part-time employment in low-wage economies and in jobs with low skills can be a sign of labor insecurity, and the type of employment contract is a clear channel for growing inequality (Görg and Görlich, 2015). In this sense, the results show how temporary employment generated by European Funds lacks a major presence in northern EU or NAFTA regions. But large shares do appear in eastern EU countries (19\%) and China (43\%). Part-time employment is also relevant to northern EU countries (31\%), although it does not seem to be linked to poor labor conditions. The results vis-à-vis part-time labor in southern and eastern EU countries are comparatively high, and some sites do have poorer labor conditions clearly when combined with other indicators, such as high shares of labor with low wages and low skills, poor conditions can dominate. Following the ILO standards, work conditions should ensure, among other things, freedom, equity, and security (Gómez-Paredes et al., 2016); our combined study of indicators including temporary and part-time employment figures appear to reveal an increase in the risk of inequality footprints emanating from activities in developed countries.

\subsection{Intra-EU impact leakages: the path to cohesion?}

As demonstrated, the dynamics enabled by the MFF differ within the EU. A deeper look at the data helps us assess whether or not the social outcomes of the funds are in line with the major European objective - enhanced cohesion of member states. To this end, we chose two socioeconomic indicators relating to income generation and hours worked by skill level in terms of a balance for the impacts, the difference between spillovers (the impact a country receives from others) and leakage (the impact that leaks from one country to others directly through imports alone) among countries (Figure 1), considering only the intra-EU impacts. Results close to zero point out countries with balanced impacts between spillover and leakage effects emanating from international specialization. The higher the positive balance, the higher the impact, direct and indirect, the member state receives from the European Funds.

Most developed countries within the EU are net exporters of high- and medium-skilled labor compensation via other EU countries' imports. That is, these net exporting countries receive more indirect impacts from the Funds than from the indirect impacts that leak from them. Germany stands out; its powerful economy obtains significant economic effects via the production of value-added intensive goods and services indirectly via demands from other EU countries. Spending of European Funds in peripheral regions reverberates strongly throughout Germany's economy. Countries such as the United Kingdom, the Netherlands, Austria, and Belgium obtain similar positive benefits from such spending. On the other side, peripheral countries leak more than spills over to them, at least in terms of labor compensation. In this instance, Poland stands out as a net importer (greater leakages) of all kinds of labor compensation. 
Figure 1. Net impact balance of labor compensation (left) and worked hours (right) footprint within the EU by skill category.

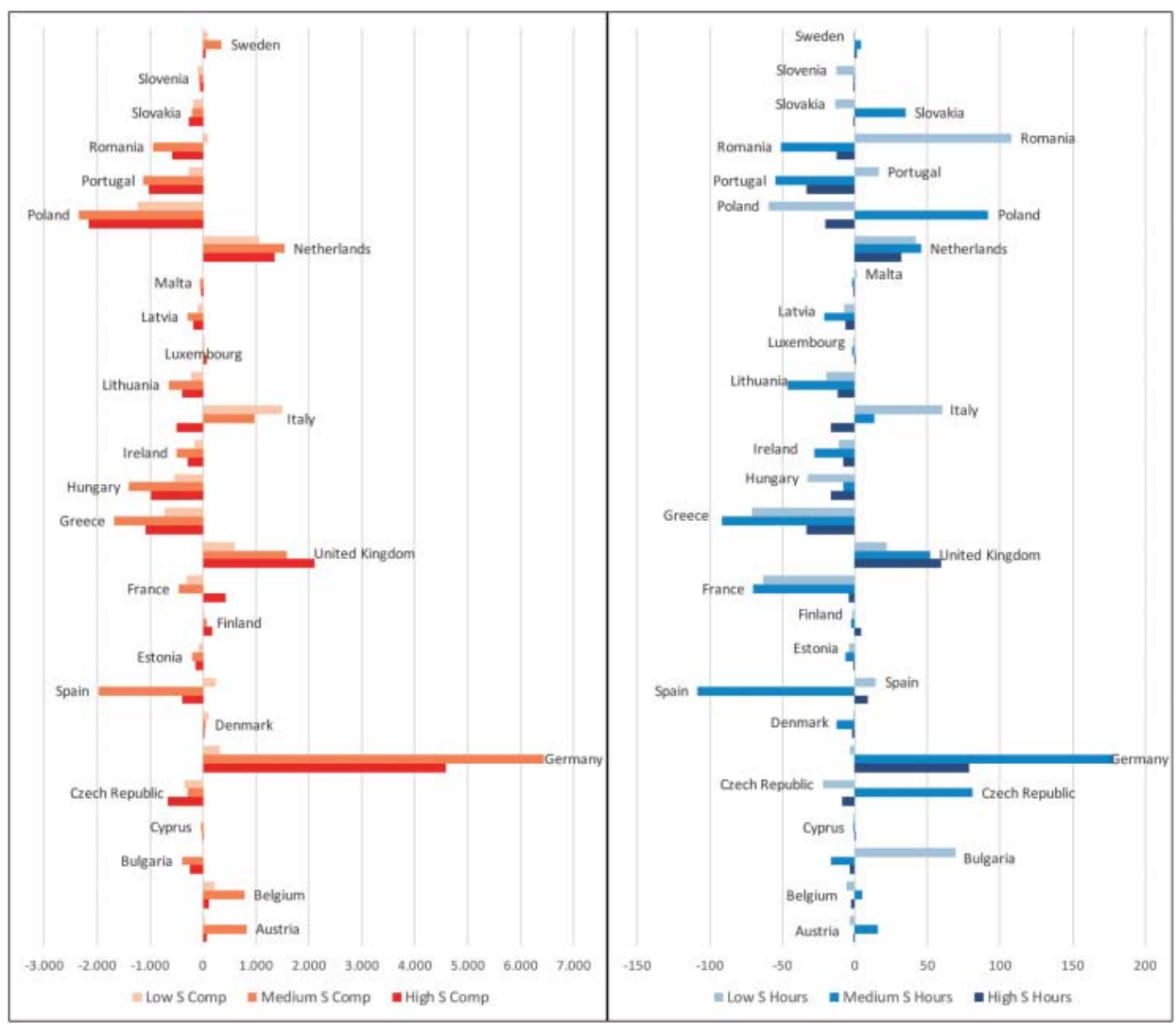

Top trading partners (Table 2) can help give some sense of the nature of the net balance. Germany and the United Kingdom are the main exporting countries (economies improved by spillovers) of high-skilled work in terms of both compensation and hours. France, a core EU country as well, is remarkable vis-à-vis spillovers but also presents noteworthy leakage of low- and medium-skilled labor compensation. Italy is another odd case but has a pattern opposite of France's, as, in net, it exports low- and medium-skilled labor compensation while, in net, it imports high-skilled labor compensation due to its inbetween position inside the EU (a developed country of the south with middling pay levels and specialized in medium- to low-skilled labor). The right-hand side of Table 2 presents the net balance of worked hours by skill, considering, again, exclusively intra-EU flows. In this case, differences between European regions are clear. Only three of the most developed European economies (Germany, the Netherlands and the United Kingdom) are net exporters of high-skilled labor hours. Southern countries (Spain, Italy, Portugal, Greece and even France) are net importers of large amounts of high- and medium-skilled labor hours, although in some cases, they are net exporters of low-skilled hours. As Table 2 shows, those flows of high- and medium-skilled labor come mainly from core countries but also from eastern EU countries, like Poland, the Czech Republic or Slovakia, which are highly specialized in medium-skilled labor hours that are embodied in the goods they export. 
Table 2. Top labor compensation and worked hours exporter and importer countries by skill category.

\begin{tabular}{|c|c|c|c|c|c|c|c|c|c|c|c|c|c|}
\hline \multicolumn{14}{|l|}{ HIGH SKILL } \\
\hline \multicolumn{7}{|c|}{ LABOR COMPENSATION } & \multicolumn{7}{|c|}{ LABOR HOURS } \\
\hline Greater LEAKS (TOP-5) & \multicolumn{6}{|c|}{ Top trading partners (\%) } & Greater LEAKS (TOP-5) & \multicolumn{6}{|c|}{ Top trading partners (\%) } \\
\hline Poland & DEU & $37 \%$ & GBR & $15 \%$ & FRA & $9 \%$ & Poland & DEU & $26 \%$ & GBR & $14 \%$ & ESP & $7 \%$ \\
\hline Spain & DEU & $28 \%$ & FRA & $21 \%$ & GBR & $12 \%$ & France & DEU & $22 \%$ & ESP & $20 \%$ & GBR & $14 \%$ \\
\hline France & DEU & $32 \%$ & GBR & $16 \%$ & ESP & $15 \%$ & Spain & DEU & $21 \%$ & FRA & $18 \%$ & GBR & $11 \%$ \\
\hline Germany & GBR & $22 \%$ & FRA & $16 \%$ & NLD & $14 \%$ & Germany & GBR & $17 \%$ & POL & $14 \%$ & FRA & $11 \%$ \\
\hline Italy & DEU & $30 \%$ & FRA & $16 \%$ & GBR & $13 \%$ & Italy & DEU & $21 \%$ & ESP & $13 \%$ & FRA & $12 \%$ \\
\hline Greater BOOSTS (TOP-5) & \multicolumn{6}{|c|}{ Top trading partners (\%) } & Greater BOOSTS (TOP-5) & \multicolumn{6}{|c|}{ Top trading partners (\%) } \\
\hline Germany & POL & $16 \%$ & FRA & $10 \%$ & ESP & $9 \%$ & Germany & POL & $16 \%$ & FRA & $10 \%$ & ESP & $9 \%$ \\
\hline United Kingdom & $\mathrm{IRL}$ & $16 \%$ & $\mathrm{POL}$ & $12 \%$ & DEU & $11 \%$ & United Kingdom & IRL & $16 \%$ & POL & $13 \%$ & DEU & $11 \%$ \\
\hline France & ESP & $19 \%$ & DEU & $12 \%$ & $\mathrm{POL}$ & $10 \%$ & Spain & PRT & $25 \%$ & FRA & $18 \%$ & ITA & $9 \%$ \\
\hline Netherlands & DEU & $12 \%$ & ESP & $10 \%$ & POL & $10 \%$ & Poland & DEU & $14 \%$ & LTU & $10 \%$ & CZE & $9 \%$ \\
\hline Spain & PRT & $26 \%$ & FRA & $17 \%$ & $\mathrm{POL}$ & $8 \%$ & France & ESP & $19 \%$ & DEU & $12 \%$ & ITA & $10 \%$ \\
\hline \multicolumn{14}{|l|}{ MEDIUM SKILL } \\
\hline \multicolumn{7}{|c|}{ LABOR COMPENSATION } & \multicolumn{7}{|c|}{ LABOR HOURS } \\
\hline Greater LEAKS (TOP-5) & \multicolumn{6}{|c|}{ Top trading partners (\%) } & Greater LEAKS (TOP-5) & \multicolumn{6}{|c|}{ Top trading partners (\%) } \\
\hline Poland & DEU & $37 \%$ & ITA & $10 \%$ & GBR & $10 \%$ & Poland & DEU & $25 \%$ & CZE & $14 \%$ & HUN & $9 \%$ \\
\hline France & DEU & $32 \%$ & ITA & $14 \%$ & GBR & $11 \%$ & Germany & $\mathrm{POL}$ & $23 \%$ & CZE & $15 \%$ & GBR & $8 \%$ \\
\hline Spain & DEU & $28 \%$ & FRA & $15 \%$ & ITA & $13 \%$ & France & DEU & $22 \%$ & $\mathrm{POL}$ & $14 \%$ & ITA & $12 \%$ \\
\hline Germany & GBR & $14 \%$ & NLD & $12 \%$ & ITA & $11 \%$ & Spain & DEU & $20 \%$ & POL & $12 \%$ & ITA & $11 \%$ \\
\hline Italy & DEU & $32 \%$ & FRA & $13 \%$ & GBR & $9 \%$ & Hungary & DEU & $21 \%$ & POL & $20 \%$ & CZE & $12 \%$ \\
\hline Greater BOOSTS (TOP-5) & \multicolumn{6}{|c|}{ Top trading partners (\%) } & Greater BOOSTS (TOP-5) & \multicolumn{6}{|c|}{ Top trading partners (\%) } \\
\hline Germany & POL & $16 \%$ & FRA & $11 \%$ & ESP & $9 \%$ & Germany & POL & $16 \%$ & FRA & $10 \%$ & ESP & $9 \%$ \\
\hline Italy & FRA & $14 \%$ & $\mathrm{POL}$ & $13 \%$ & ESP & $13 \%$ & Poland & DEU & $14 \%$ & LTU & $10 \%$ & CZE & $9 \%$ \\
\hline United Kingdom & IRL & $16 \%$ & $\mathrm{POL}$ & $12 \%$ & DEU & $11 \%$ & Italy & FRA & $14 \%$ & $\mathrm{POL}$ & $13 \%$ & ESP & $13 \%$ \\
\hline France & ESP & $18 \%$ & DEU & $12 \%$ & ITA & $11 \%$ & United Kingdom & IRL & $16 \%$ & $\mathrm{POL}$ & $12 \%$ & DEU & $11 \%$ \\
\hline Netherlands & DEU & $14 \%$ & FRA & $10 \%$ & $\mathrm{POL}$ & $9 \%$ & Hungary & POL & $16 \%$ & ROU & $11 \%$ & DEU & $11 \%$ \\
\hline
\end{tabular}

(continued) 
Table 2. Continued.

\section{LOW SKILL}

\begin{tabular}{|c|c|c|c|c|c|c|c|c|c|c|c|c|c|}
\hline \multicolumn{7}{|c|}{ LABOR COMPENSATION } & \multicolumn{7}{|c|}{ LABOR HOURS } \\
\hline \multirow{2}{*}{$\begin{array}{l}\text { Greater LEAKS (TOP-5) } \\
\text { France }\end{array}$} & \multicolumn{6}{|c|}{ Top trading partners (\%) } & \multicolumn{3}{|l|}{ Greater LEAKS (TOP-5) } & \multicolumn{4}{|c|}{ Top trading partners (\%) } \\
\hline & ITA & $24 \%$ & ESP & $22 \%$ & DEU & $11 \%$ & France & ESP & $24 \%$ & ITA & $18 \%$ & ROU & $11 \%$ \\
\hline Poland & ITA & $22 \%$ & DEU & $17 \%$ & GBR & $11 \%$ & Spain & PRT & $30 \%$ & ITA & $16 \%$ & ROU & $10 \%$ \\
\hline Spain & ITA & $22 \%$ & PRT & $17 \%$ & FRA & $15 \%$ & Poland & ITA & $17 \%$ & ROU & $14 \%$ & DEU & $13 \%$ \\
\hline Germany & ITA & $20 \%$ & NLD & $16 \%$ & ESP & $12 \%$ & Germany & ITA & $15 \%$ & ROU & $13 \%$ & ESP & $12 \%$ \\
\hline Greece & ITA & $31 \%$ & DEU & $10 \%$ & NLD & $8 \%$ & Italy & ROU & $23 \%$ & ESP & $17 \%$ & DEU & $9 \%$ \\
\hline Greater BOOSTS (TOP-5) & \multicolumn{6}{|c|}{ Top trading partners (\%) } & Greater BOOSTS (TOP-5) & \multicolumn{6}{|c|}{ Top trading partners (\%) } \\
\hline Italy & FRA & $15 \%$ & $\mathrm{POL}$ & $13 \%$ & ESP & $13 \%$ & Romania & HUN & $12 \%$ & ITA & $12 \%$ & $\mathrm{POL}$ & $10 \%$ \\
\hline Spain & PRT & $25 \%$ & FRA & $20 \%$ & ITA & $9 \%$ & Italy & FRA & $15 \%$ & $\mathrm{POL}$ & $13 \%$ & ESP & $13 \%$ \\
\hline Germany & POL & $16 \%$ & FRA & $11 \%$ & ESP & $9 \%$ & Spain & PRT & $24 \%$ & FRA & $21 \%$ & ITA & $10 \%$ \\
\hline United Kingdom & $\mathrm{IRL}$ & $16 \%$ & POL & $12 \%$ & FRA & $11 \%$ & Germany & $\mathrm{POL}$ & $15 \%$ & FRA & $10 \%$ & ESP & $9 \%$ \\
\hline France & ESP & $18 \%$ & DEU & $12 \%$ & ITA & $11 \%$ & Bulgaria & GRC & $30 \%$ & ROU & $16 \%$ & $\mathrm{POL}$ & $7 \%$ \\
\hline
\end{tabular}

Sources: Own estimations.

Notes: CZE: Czech Republic. DEU: Germany. ESP: Spain. FRA: France. GBR: United Kingdom. GRC: Greece. HUN: Hungary. IRL: Ireland. ITA: Italy. LTU: Lithuania. NLD: Netherlands. POL: Poland. PRT: Portugal. ROU: Romania. Only considered intra-EU flows. Top 5 LEAKS allude to top net importing countries and Top 5 BOOSTS to top net exporting countries because of the EU Fund's expenditures. 
Figure 2. Worldwide flows of Labor Compensation (million euros) and Worked hours (million) by skill category.

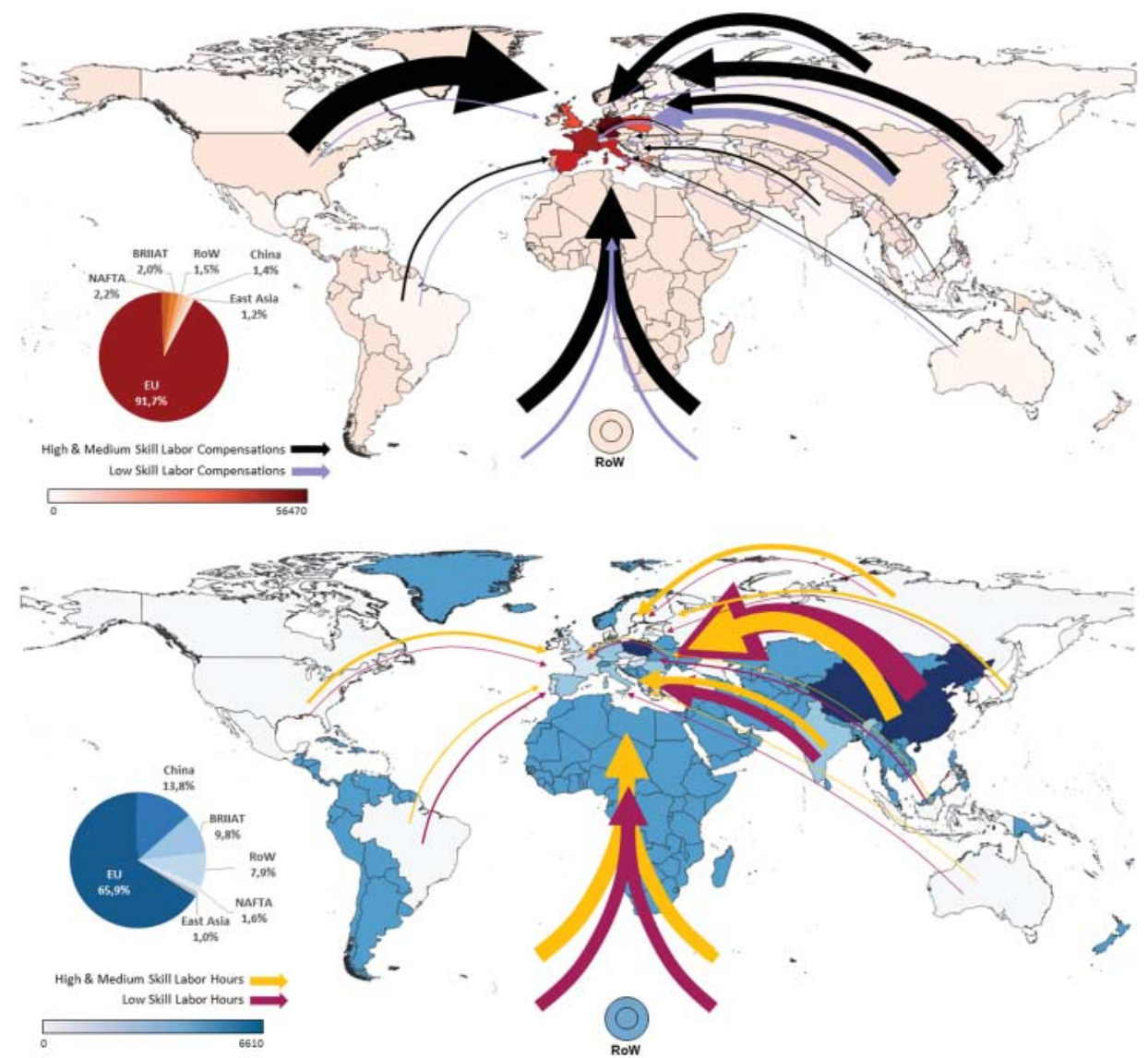

Note: Note to upper Figure: The color scale on the background map represents the labor compensation boost received by each region (all skill levels). The arrows depict labor compensation flows by skill level embodied in EU imports from foreign regions. The graphic on the left shows the participation of each origin region (including the EU) in the total labor compensation footprint of the EU. Note to lower Figure: The color scale on the background map represents the labor hours boost received by each region (all skill levels). The arrows depict physical labor flows by skill level embodied in EU imports from foreign regions. The graphic on the left shows the participation of each origin region (including the EU) in total labor hours footprint of the EU.

Their spatial proximity to Germany economic influence underlie these results (Bruno et al., 2012). At the extreme other end of the scale, Romania and Bulgaria stand out as transition economies via net exportation of low-skilled labor hours; indeed, they are among the top-five exporting countries of such labor to other peripheral countries (Table 2). These outcomes show that even within eastern Europe, different patterns of labor specialization exist that yield different economic structures.

A look at both sides of Table 2 reveals the unequal distribution of value added generated and labor hours required to produce the goods and services demanded by European countries. Labor compensation is more widely spread among European countries than are labor 
hours, which concentrate in eastern EU. This divergence exemplifies the wage gap inside the EU: while income spillovers benefit most countries, especially those at the EU core, physical labor behind that production concentrates in EU transition economies which tend to have lower salaries. The positive economic effects of the Funds are not only dispensed to those countries that physically receive the Funds but also to core EU countries with more developed trade structures. This result in three types of impacts, which can be classified by the type of region: EU core countries, EU peripheral countries and the RoW.

\subsection{Outer-EU impact leakages: a sustainable social footprint?}

From a global perspective, there is a clear distinction between the leakages of total jobs (34\%) and labor compensation (8\%). We find that some producer's search for comparative advantages in terms of low worker pay. A main exporting region of high- and mediumskilled labor compensation is the set of NAFTA countries, followed distantly by the RoW's regions (black arrows in upper Map in Figure 2). The main exporter of low-skilled labor compensation is China (purple arrows). By contrast, low-skilled workers from developing countries (lower map in Figure 2) provide major flows of physical labor to supply EU demands. China again stands out: its labor compensation is a minor participant in global monetary flows (1.4\%); but its share of work hours embodied in imports (13.8\%) reveal it is a major player. Similar patterns are observed for the case of the BRIIAT and RoW regions. The finding for NAFTA countries are quite the opposite when comparing the physical and monetary flows. So we conclude that final demand triggered by the European Funds induces significant income spillovers for NAFTA countries, although it requires a surprising amount of physical labor from Asia and other emerging economies. The wage gap between the regions underlies those results. The results for NAFTA countries are comparable to the leakage from the most developed regions within the EU. They reveal that substantial inequality is promoted by European demand. This leads us to question the alignment of EU principles with the indirect demand-side effects of European Funds' allocations.

\section{Conclusions}

EU financial efforts have benefited both developed and less developed member countries. So, the Emperor is definitely enrobed. But, in the light of the analysis herein, it appears not to be the sort of robe that should be proudly paraded about in public. That is, from a social perspective, the consequences of EU expenditures are not aligned with EU guiding principles. That is, the intensity of trade relationships within the EU affects demand-side outcomes that yield unintended consequences. So, the spending of EU funds yields firstand second-class winners that align with core and peripheral economies rather than with the original distribution of those funds.

We show that both economic differences in economic structure among EU regions and each country's relative position within global supply chains redirect the economic effects of European financial efforts to benefit its more disadvantaged economies. Thus, within this framework, more advanced EU member countries paradoxically benefit much more from the EU spending than expected. They benefit from a more mature economic structure, which positions them as hubs of EU activity benefit more from their own and 
other countries' EU public investments. Baldwin (2013) suggests that core economies' exports contain a comparatively small shares of imported intermediates, while peripheral economies' exports contain higher shares. EU Funds leak from less powerful peripheral economies to the EU core since their economic structure is not able to meet demands of the EU Funds on their own. The leakage from these countries therefore boosts the more mature economies for most of the important positive indicators in our analysis, e.g. income generation and distribution, and the creation of high- and medium-skilled jobs. Meanwhile more working hours are generated in the eastern section of the EU, in labor-intensive industries with lower quality jobs. Thus relative wealth is built up in the EU core.

Widening the scope, there are also other unintended consequences worldwide that deserve scrutiny. The spending of European Funds triggers much greater increases in capital compensation than in labor compensation in regions such as China, RoW or BRIIAT, although a disproportionate number of the working hours is generated in China. Most of the affected emerging countries are contributing via industries that are labor intensive. The results are driven by the low rates of pay as well as the rising presence of multinational and subsidiary firms in developed countries. Unfortunately, these same nations are affiliated with poorer working conditions, reflected in significant large number of low-skilled working hours and temporary jobs created there via the EU funds.

This study leads us to conclude that globalization is threatening, the EU's high social mores that are fundamental to the Union's policies. This is the case of social outcomes even within its own borders. The solution is not a matter of constraining free trade; rather, it means that, at least, more care should be taken so that expenditures funded by the EU are assured to be committed to those standards. Our analysis helps to identify holes in the value chains of peripheral countries that appear to severely alter the effects of EU programs. We, therefore, suggest that tooled with knowledge of probable outcomes from alternative uses of EU Funds, policymakers could sharpen investments toward the goal of improving the sustainability of the EU economy through its global value chains. Further research should be undertaken to assess the ultimate supply-side effects triggered by the European policies to enhance productivity gains. In the case of the EU, such measures could help strengthen the EU target of intercountry convergence of GDP per capita. They could be designed to minimize the income leakages from southern and eastern EU member countries to their northern partners. Actions to enhance European labor markets, particularly those regarding education and improving worker skills, should be a major focus as well. Policies should be directed not only toward alleviating wage gaps but also toward reducing differences in labor market flexibility and toward increasing employment opportunities for labor with higher skill levels. In particular, the target of cohesion can only be fulfilled if more flexible structures in southern and eastern EU countries are accompanied by a transition to more efficient and innovative work force. This would improve the workers' professional qualifications as well as the working conditions of labor there. If such a transition is not undertaken, flexibility could facilitate labor insecurity, a trap that reared its ugly head in the wake of the financial and economic crisis in a number of the countries in Europe's south and east.

Actions to address issues beyond EU borders are far more complex to address. The intricate economic, financial and trade networks present challenge in terms of global socioeconomic sustainability. EU policy should address actions in line with the sustainable public procurement and ensure that the global activity of EU firms and consumers is 
based on principles in line with EU social, economic and environmental mores. EU multinational firms should do more to inform the public about their activity abroad so citizens can assess the extent of the social drag caused by multinationals and institutions. In this way such organizations will be motivated to do their best under principles of not only economic cost-effectiveness but also social cost-effectiveness.

\section{Disclosure statement}

No potential conflict of interest was reported by the authors.

\section{Funding}

This work was supported by Ministerio de Economía y Competitividad (ECO2016-78938-R) and Regional Government of Castilla-La Mancha (PPII-2014-006-P).

\section{ORCID}

Fabio Monsalve (D) http://orcid.org/0000-0001-6595-2799

Jorge Zafrilla (i) http://orcid.org/0000-0001-7953-9006

María-Ángeles Cadarso (D) http://orcid.org/0000-0002-5165-7729

\section{References}

Alatriste-Contreras, M.G. (2015) The Relationship Between the Key Sectors in the European Union Economy and the Intra-European Union Trade. Journal of Economic Structures, 4, 14.

Alsamawi, A., J. Murray and M. Lenzen (2014a) The Employment Footprints of Nations. Journal of Industrial Ecology, 18, 59-70.

Alsamawi, A., J. Murray, M. Lenzen, D. Moran, K. Kanemoto and R. Huerta-Quintanilla (2014b) The Inequality Footprints of Nations: A Novel Approach to Quantitative Accounting of Income Inequality. PloS One, 9.

Alsamawi, A., J. Murray, M. Lenzen and R.C. Reyes (2017) Trade in Occupational Safety and Health: Tracing the Embodied Human and Economic Harm in Labour Along the Global Supply Chain. Journal of Cleaner Production, 147, 187-196.

Andritzky, J., B. Kassner and W.H. Reuter (2016) Propagation of changes in demand through international trade: Case study China (Working paper No. 10/2016, Sachverständigenrat zur Begutachtung der Gesamtwirtschaftlichen Entwicklung).

Baldwin, R. (2013) Global Supply Chains: why They Emerged, why They Matter, and Where They are Going. Chapter 1. In: D.K. Elms and P. Low (eds.) Global Value Chains in a Changing World. Geneva, Switzerland: World Trade Organization Geneva, 11-59.

Baldwin, R. and J. Lopez-Gonzalez (2015) Supply-chain Trade: A Portrait of Global Patterns and Several Testable Hypotheses. The World Economy, 38, 1682-1721.

Bems, R., R.C. Johnson and K.-M. Yi (2010) Demand Spillovers and the Collapse of Trade in the Global Recession. IMF Economic Review, 58, 295-326.

Bonnet, F., J.B. Figueiredo and G. Standing (2003) A Family of Decent Work Indexes. International Labour Review, 142, 213-238.

Bruno, G.S., R. Crinò. and A.M. Falzoni (2012) FDI, Trade, and Skilled Labour Demand in Eastern Europe. Labour, 26, 492-513.

Cadarso, M.-Á., L.-A. López, N. Gómez and M.-Á. Tobarra (2012) International Trade and Shared Environmental Responsibility by Sector. An Application to the Spanish Economy. Ecological Economics, 83, 221-235.

Cerina, F., Z. Zhu, A. Chessa, M. Riccaboni and I. Sendina-Nadal (2015) World Input-Output Network. PloS One, 10, e0134025. 
Davis, S.J. and K. Caldeira (2010) Consumption-Based Accounting of $\mathrm{CO}_{2}$ Emissions. Proceedings of the National Academy of Sciences, 107, 5687-5692.

Dietzenbacher, E., M. Lenzen, B. Los, D. Guan, M.L. Lahr, F. Sancho, S. Suh and C. Yang (2013) Input-Output Analysis: The Next 25 Years. Economic Systems Research, 25, 369-389.

Erumban, A.A., R. Gouma, G. de Vries, K. de Vries and M.P. Timmer (2012) WIOD socio-economic accounts (SEA): Sources and methods (Unpublished paper. University of Groningen). Accessed June 2018. http://www.wiod.org/publications/source_docs/SEA_Sources.pdf.

European Commission (2015) EU expenditure and revenue 2007-2013. Accessed June 2018. http://ec.europa.eu/budget/financialreport/2013/foreword/index_en.html

European Commission (2016) EUROSTAT. Accessed June 2018. http://ec.europa.eu/eurostat

EUROSTAT (2017a) Employment and unemployment (Labour force survey). http://ec.europa.eu/ eurostat/cache/metadata/EN/employ_esms.htm\#coher_compar1495532395031

EUROSTAT (2017b) LFS main indicators (lfsi). Accessed June 2018. http://ec.europa.eu/eurostat/ cache/metadata/en/lfsi_esms.htm

Feenstra, R.C. (2007) Globalization and its impact on labour (Working Paper No. 44, Wiener Institut für Internationale Wirtschaftsvergleiche, Vienna).

Foran, B., M. Lenzen, C. Dey and M. Bilek (2005) Integrating Sustainable Chain Management with Triple Bottom Line Accounting. Ecological Economics, 52, 143-157.

Gómez-Paredes, J., A. Alsamawi, E. Yamasue, H. Okumura, K.N. Ishihara, A. Geschke, and M. Lenzen (2016) Consuming Childhoods: An Assessment of Child Labor's Role in Indian Production and Global Consumption. Journal of Industrial Ecology, 20, 611-622.

Gómez-Paredes, J., E. Yamasue, H. Okumura and K.N. Ishihara (2015) The Labour Footprint: A Framework to Assess Labour in a Complex Economy. Economic Systems Research, 27, $1-25$.

Görg, H. and D. Görlich (2015) Offshoring, Wages and job Security of Temporary Workers. Review of World Economics, 151, 533-554.

Hardadi, G. and M. Pizzol (2017) Extending the Multiregional Input-Output Framework to LaborRelated Impacts: A Proof of Concept. Journal of Industrial Ecology, 21, 1536-1546.

Hobza, A., S. Zeugner and J. N. Martins, eds. (2012) Current account surpluses in the EU (European Economy Series Report 9/2012, Directorate General for Economic and Financial Affairs, European Comission, Brussels).

ILO. (2016). ILOSTAT. Available online in June 2018 at www.ilo.org/ilostat.

Kali, R. and J. Reyes (2007) The Architecture of Globalization: a Network Approach to International Economic Integration. Journal of International Business Studies, 38, 595-620.

Kireyev, A. and A. Leonidov. (2015) Network effects of international shocks and spillovers (IMF Working Paper WP/15/149, International Monetary Fund, Washington, DC).

Kireyev, A. and A. Leonidov. (2016). China's imports slowdown: Spillovers, spillins, and spillbacks (IMF Working Paper WP/16/51, International Monetary Fund, Washington, DC).

Kucukvar, M., G. Egilmez and O. Tatari (2014) Sustainability Assessment of U.S. Final Consumption and Investments: Triple-Bottom-Line Input-Output Analysis. Journal of Cleaner Production, 81, 234-243.

Los, B., M.P. Timmer and G.J. de Vries (2015) How Global are Global Value Chains? A new Approach to Measure International Fragmentation. Journal of Regional Science, 55, 66-92.

McBain, D. (2014) Social Indicators for use with Multi-Regional input-output Analysis (Unpublished Ph.D, dissertation, Faculty of Science, School of Physics, University of Sidney). Accessed June 2018. http://hdl.handle.net/2123/12891.

Meng, B., G. Peters, and Z. Wang (2014) Tracing $\mathrm{CO}_{2}$ Emissions in Global Value Chains (Office of Economics Working Paper No. 2014-12a, U.S. International Trade Commission, Washington, DC).

Miller, R.E. and P.D. Blair (2009) Input-output Analysis: Foundations and Extensions. Cambridge: Cambridge University Press.

Monsalve, F., J.E. Zafrilla and M.-Á. Cadarso (2016) Where Have all the Funds Gone? Multiregional Input-Output Analysis of the European Agricultural Fund for Rural Development. Ecological Economics, 129, 62-71. 
Pelletier, N., E. Ustaoglu, C. Benoit, G. Norris, E. Rosenbaum, A. Vasta, and S. Sala (2018) Social sustainability in trade and development policy. The International Journal of Life Cycle Assessment, 23, 629-639.

Picek, O. and E. Schröder (2017) Spillover Effects of Germany's Final Demand on Southern Europe (IMK Working Paper No. 181, Hans-Böckler-Stiftung, Macroeconomic Policy Institute, Düsseldorf, Germany).

Priede, J. and J. Neuert (2015) Competitiveness gap of the European Union Member Countries in the Context of Europe 2020 Strategy. Procedia - Social and Behavioral Sciences, 207, 690-699.

Rakauskiene, O.G. and V. Kozlovskij (2014) Overview of EU Economic Cohesion Process Performance for new Member States. Procedia - Social and Behavioral Sciences, 110, 284-292.

Rodríguez-Serrano, I., N. Caldés, C. De La Rúa, Y. Lechón and A. Garrido (2016) Using the Framework for Integrated Sustainability Assessment (FISA) to Expand the Multiregional Input-Output Analysis to Account for the Three Pillars of Sustainability. Environment, Development and Sustainability, 19, 1981-1997.

Simas, M., L. Golsteijn, M. Huijbregts, R. Wood and E. Hertwich (2014) The 'bad Labor' Footprint: Quantifying the Social Impacts of Globalization. Sustainability, 6, 7514-7540.

Skelton, A., D. Guan, G.P. Peters and D. Crawford-Brown (2011) Mapping Flows of Embodied Emissions in the Global Production System. Environmental Science \& Technology, 45, 10516-10523.

Steen-Olsen, K., J. Weinzettel, G. Cranston, A.E. Ercin and E.G. Hertwich (2012) Carbon, Land, and Water Footprint Accounts for the European Union: Consumption, Production, and Displacements Through International Trade. Environmental Science \& Technology, 46, 10883-10891.

The World Bank. (2016) World Development Indicators. Accessed June 2018. https://data.worldbank. org/products/wdi.

Timmer, M.P., E. Dietzenbacher, B. Los, R. Stehrer and G.J. de Vries (2015) An Illustrated User Guide to the World Input-Output Database: The Case of Global Automotive Production. Review of International Economics, 23, 575-605.

Tran, T.K., H. Sato, and A. Namatame. (2017) Key Economic Sectors and Their Transitions: Analysis of World Input-Output Network. In: V. Kreinovich, S. Sriboonchitta and V.-N. Huynh (eds.) Robustness in Econometrics. Heidelberg, Springer International Publishing, 381-399.

Vaughan-Whitehead, D. (2015) The European Social Model in Times of Crisis: An Overview. Chapter 1. In D. Vaughan-Whitehead (ed.) The European Social Model in Crisis: Is Europe Losing Its Soul? Chentenham, UK, Edward Elgar, 9-60.

Wiedmann, T. (2015) Impacts Embodied in Global Trade Flows. In: R. Clift and A. Druckman (eds.) Taking Stock of Industrial Ecology. Heidelberg, Springer International Publishing, 159-180.

Wiedmann, T., H.C. Wilting, M. Lenzen, S. Lutter and V. Palm (2011) Quo Vadis MRIO? Methodological, Data and Institutional Requirements for Multi-Region Input-Output Analysis. Ecological Economics, 70, 1937-1945.

Wiedmann, T., H. Schandl, M. Lenzen, D. Moran, S. Suh, J. West and K. Kanemoto (2013) The Material Footprint of Nations. Proceedings of the National Academy of Sciences, 112, 6271-6276.

Wood, R. and S. Garnett (2010) Regional Sustainability in Northern Australia - A Quantitative Assessment of Social, Economic and Environmental Impacts. Ecological Economics, 69, $1877-1882$.

Xiao, Y., M. Lenzen, C. Benoît-Norris, G.A. Norris, J. Murray and A. Malik (2017a) The Corruption Footprints of Nations. Journal of Industrial Ecology, 22, 68-78.

Xiao, Y., C.B. Norris, M. Lenzen, G. Norris and J. Murray (2017b) How Social Footprints of Nations can Assist in Achieving the Sustainable Development Goals. Ecological Economics, 135, 55-65. 